Syntax Literate: Jurnal Ilmiah Indonesia p-ISSN: 2541-0849

e-ISSN: 2548-1398

Vol. 5, No. 8, Agustus 2020

\title{
PERANCANGAN APLIKASI PENGENALAN ALAT-ALAT PRAKTIK LABORATORIUM KIMIA BERBASIS AUGMENTED REALITY
}

\section{Syahril Amin}

Program Studi Ilmu Komputer STIMIK Kreatindo Manokwari

Email: syahril.amin.ari@gmail.com

\begin{abstract}
Implementation of Augmented Reality technology in Education, particularly in Elementary to Senior High School, generally still use the marker as a trigger to display information on the smartphone screen to support the learning and teaching process. This research will be developed AR Technology based on Android by using an object as a trigger to display information on the Smartphone screen. The result of the design will invent an application that can be used to identify practice tools in the chemistry school laboratory. The results showed that the application of Chemical tools can be a non-transparent display that does not reflect light and shadow of the surrounding objects with a percentage of $71.42 \%$, and also it is able to reflect light and shadow objects around it with the percentage of $52.38 \%$.
\end{abstract}

Keywords: Augmented Reality; Marker; Chemical Tools

\begin{abstract}
Abstrak
Penerapan teknologi $A R$ dalam dunia Pendidikan, khususnya pada Sekolah Dasar sampai Sekolah Menengah Atas, untuk mendukung proses belajar mengajar, pada umumnya masih menggunakan marker penanda sebagai pemicu untuk menampilkan informasi pada layar smartphone. Pada penelitian ini akan dikembangkan teknolgi $A R$ berbasis Android dengan menggunakan objek sebagai pemicu untuk menampilkan informasi di layar Smartphone. Hasil penelitian menunjukkan aplikasi Alat Kimia dapat mendeteksi dan mengenali objek dengan sifat permukaan tidak transparan yang tidak memantulkan cahaya dan bayangan benda di sekitarnya dengan persentase $71.42 \%$, serta dapat mendeteksi dan mengenali objek dengan sifat permukaan tidak transparan yang dapat memantulkan cahaya dan bayangan benda di sekitarnya dengan persentase $52.38 \%$.
\end{abstract}

Kata kunci: Augmented Reality; Marker; Alat Praktik Kimia

\section{Pendahuluan}

Penemuan dan pengembangan ilmu pengetahuan dalam bidang informasi dan komunikasi yang mampu menciptakan perangkat yang mendukung perkembangan teknologi informasi, mulai dari sistem komunikasi sampai dengan alat komunikasi yang searah maupun dua arah (interaktif), telah memberikan keunggulan kompetitif secara global. Salah satu model komunikasi adalah model komunikasi dua arah. Apabila terdapat dua pihak yang berkomunikasi maka keduanya dapat berperan sebagai 
komunikator dan komunikan secara bergantian, saling mengirim pesan dan menerima pesan secara berkelanjutan (Prastiwi \& Yuniasanti, 2014).

Sebagai sebuah teknologi, teknologi informasi dan komunikasi juga selain memiliki dampak negatif juga memiliki dampak positif bagi penggunanya. Dengan menawarkan keragaman manfaat teknologi informasi dan komunikasi diharapkan dapat mengikis dampak negatifnya. Dan salah satu upaya yang dapat dilakukan adalah meningkatkan pemanfaatan alat-alat teknologi informasi dan komunikasi sebagai media dan alat bantu dalam proses belajar-mengajar di kelas. Dengan mengenal media pengajaran dan memahami cara-cara penggunaannya akan sangat membantu tugas para guru dalam meningkatkan efektivitas proses pembelajaran. Pemanfaatan media animasi yang merupakan bagian dari multimedia diharapkan dapat membantu proses pembelajaran sehingga peserta didik dapat beraktivitas mengoptimalkan kongnitifnya (Hambali, Akib, \& Azis, 2020).

Kecepatan perkembangan teknologi masuk kesemua lini dan sendi aktivitas manusia baik pribadi atau kelompok (badan). Jika dulu manusia dalam berkomunikasi harus selalu bertatap muka, tetapi kini komunikasi terjadi tanpa ada batas ruang dan waktu (Abdurokhim, 2016)

Saat ini, perkembangan teknologi informasi dan komunikasi telah mewabah di kalangan masyarakat umum. Salah satu contoh dari pekembangannya teknologi adalah Augmented Reality (AR). AR merupakan upaya untuk menggabungkan dunia nyata dan dunia virtual yang dibuat melalui komputer sehingga jarak antara keduanya akan sangat tipis (Angriani, 2020). Seiring berjalannya waktu, AR berkembang sangat pesat sehingga memungkinkan pengembangan aplikasi ini di berbagai bidang termasuk pendidikan dan hiburan (Yudiantika, Pasinggi, Sari, \& Hantono, 2013).

Augmented Reality atau yang biasa disebut dengan AR merupakan sebuah teknologi untuk memadukan dunia nyata dan dunia virtual secara realtime dengan sebuah objek nyata yang berfungsi sebagai penanda untuk penentuan posisi objek virtual yang telah teridentifikasi oleh kamera. Augmented Reality dibuat dengan komputer untuk menghasilkan sebuah keadaan yang menampilkan objek nyata dengan objek maya (virtual) pada sebuah dimensi baru.

Konsepnya adalah menggabungkan dimensi dunia nyata dengan dimensi 'dunia nyata' yang termediasi, atau dunia virtual, untuk menciptakan kesan bahwa dimensi dunia nyata kita diperkaya dengan objek maya tiga dimensi. Hal ini dilakukan dengan cara 'menggambar' objek tiga dimensi pada marker, yakni sebuah 'pola' dalam bingkai segi empat yang bersifat unik dan dapat dikenali oleh aplikasinya. Aplikasi yang bersangkutan menerima input berupa video stream, yang berarti menggunakan input berupa citraan dari perangkat keras yang berfungsi menangkap gambar, biasanya sebuah webcam. Karena berupa video stream, artinya gambaran yang ditangkap sebagai input akan berubah-ubah, dan program harus dapat tetap mengenali marker meskipun berubah posisi dan orientasi relatif terhadap perangkat input. Pengenalan terhadap posisi dan pergerakan ini adalah salah satu konsep Teknologi Informasi yang bernama Computer 
Vision, dan digunakan untuk mendeteksi pola pergerakan relatif objek terhadap kamera (Hidayat, 2014).

AR bukan merupakan teknologi baru. Teknologi ini telah ada selama hampir 40 tahun, setelah diperkenalkan aplikasi Virtual Reality (VR) untuk pertama kalinya (Chafied, Hakkun, \& Asmara, 2010). Seiring berjalannya waktu, AR berkembang sangat pesat sehingga memungkinkan pengembangan aplikasi ini di berbagai bidang termasuk pendidikan.

Saat ini banyak literatur-literatur yang menunjukkan penggunaan AR di bidang pendidikan. AR dapat diterapkan dalam pengajaran tentang geometri, hubungan spasial antar planet dan struktur molekul serta identifikasi objek.

Pemanfaatan media pendidikan menggunakan AR dapat merangsang pola pikir peserta didik dalam berpikiran kritis terhadap sesuatu masalah dan kejadian yang ada pada keseharian, karena sifat dari media pendidikan adalah membantu peserta didik dalam proses pembelajaran dengan ada atau tidak adanya pendidik dalam proses pendidikan, sehingga pemanfaatan media pendidikan dengan augmented reality dapat secara langsung memberikan pembelajaran dimanapun dan kapanpun peserta didik ingin melaksanakan proses pembelajaran (Mustaqim, 2016).

Kelebihan dari Augmented Reality adalah lebih interaktif, efektif dalam penggunaan, dapat diimplementasikan secara luas dalam berbagai media, modeling obyek yang yang sederhana karena hanya menampilkan beberapa obyek, pembuatan yang tidak memakan terlalu banyak biaya dan mudah untuk dioperasikan. Sedangkan kekurangan dari Augmented Reality adalah sensitif dengan perubahan sudut pandang, pembuat belum terlalu banyak dan membutuhkan banyak memori pada peralatan yang dipasang (Mustaqim, 2017).

Penerapan AR dalam membuat media pendidikan pada umumnya diimplementasikan dengan memindai marker untuk menampilkan objek virtual 3D sehingga perlu dilakukan penelitian untuk menampilkan objek virtual 3D yang menggunakan objek nyata berupa benda dalam dunia nyata (markerless), yaitu alat-alat praktik laboratorium Kimia.

Markerless Augmented Reality merupakan salah satu metode AR tanpa menggunakan frame marker sebagai obyek yang dideteksi dan di dukung teknik Pattern Recognition (Pengenalan Pola), maka penggunaan marker sebagai tracking object tergantikan dengan permukaan suatu objek penanda sebagai tracking object (obyek yang dilacak) (Vitono, Nasution, \& Anra, 2016).

Objek nyata dapat dikenali dengan menerapkan salah satu metode image processing, yaitu object recognition. Object recognition merupakan salah satu image processing untuk mengenali objek-objek untuk diolah lebih lanjut agar mendapatkan suatu informasi. Dengan adanya proses pengenalan objek tersebut, manusia akan di permudah dalam mengenali bentuk dari objek seperti pemetaan geografis, penggunaan sensor pada benda untuk sistem keamanan, pembacaan citra hasil scan medis (Saputra, 2016). Sebuah paper dirancang sebuah aplikasi yang digunakan untuk mempresentasikan objek tiga dimensi pada leaflet/brosur dengan memanfaatkan 
augmented reality sebagai alat bantu. Alat bantu yang digunakan untuk mempresentasikan objek 3D dan informasinya ialah Vuforia SDK dan Engine Unity 3D. Gambar yang digunakan untuk menampilkan objek 3D diupload ke vuforia. Proses selanjutnya memberikan corner point dan koordinat dengan menggunakan algoritma FAST sehingga gambar ini memiliki koordinat dan corner point yang unik (Fam \& Grohs, 2007).

Penelitian lain yang berjudul "Machine Learning for high-speed Corner Detection" oleh Edward Rosten dan Tom Drummond yang dilakukan di Fakultas Teknik Cambridge University UK. Penelitian ini dilakukan dengan cara membandingkan beberapa algoritma untuk mengenal sudut dari sebuah image. Algoritma yang dibandingkan antara lain FAST, Harris, Shi \& Tomasi, DoG, HarrisLaplace, dan SUSAN Algorithm. Hasil dari penelitian ini menyatakan bahwa algoritma tercepat yang dapat menganalisis corner adalah algoritma FAST (Features from Accelerated Segment Test) (Rosten \& Drummond, 2006).

Berdasarkan latar belakang di atas, penelitian ini akan menggunakan augmented reality sebagai alat untuk memanggil menampilkan Nama dan Fungsi alat-alat praktik laboratorium kimia, Unity sebagai Application Builder dan Vuforia SDK sebagai library Augmented Reality yang didalamnya terdapat algoritma FAST Corner Detection. Hasil akhir dari penelitian ini dapat membangun Aplikasi Pengenalan Alat-alat Praktik Laboratorium Kimia dengan mengimplementasikan teknologi Augmented Reality (AR) berbasis android dengan menggunakan algoritma FAST Corner Detection. Dengan menerapkan algoritma ini diharapkan Augmented Reality dapat berjalan dengan optimal sehingga dengan device yang memiliki spesifikasi kecil seperti smartphone dapat digunakan untuk aplikasi ini.

\section{Metode Penelitian}

Metode yang digunakan pada penelitian ini adalah Prototyping Model.

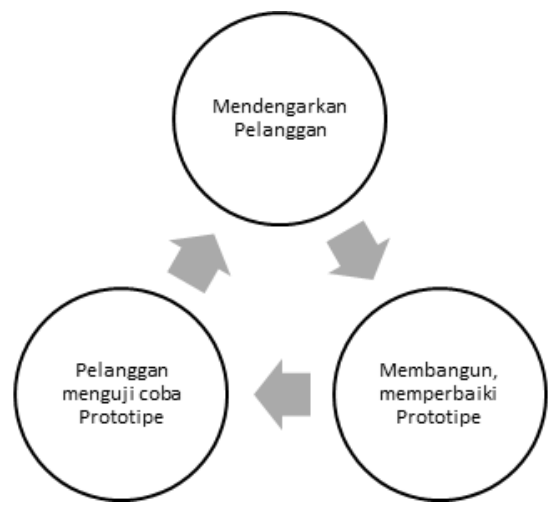

\section{Gambar 1 Prototyping Model}

Prototyping Model adalah model pengembangan software yang bertujuan untuk menciptakan aplikasi pertama dengan cepat sebagai representasi dari aplikasi yang 
sebenarnya. Metode ini digunakan untuk menyelesaikan kesalahpahaman antara pengguna dan pengembang yang timbul akibat pengguna tidak mampu mendefinisikan kebutuhannya secara jelas.

Prototyping merupakan metode pengembangan perangat lunak, yang berupa model fisik kerja sistem dan berfungsi sebagai versi awal dari sistem. Dengan metode prototyping ini akan dihasilkan prototype sistem sebagai perantara pengembang dan pengguna agar dapat berinteraksi dalam proses kegiatan pengembangan sistem informasi. Agar proses pembuatan prototype ini berhasil dengan baik adalah dengan mendefinisikan aturan-aturan pada tahap awal, yaitu pengembang dan penguna harus satu pemahaman bahwa prototype dibangun untuk mendefinisikan kebutuhan awal (Ogedebe \& Jacob, 2012).

Penelitian ini akan dimulai dengan melakukan pembandingan dengan sistem yang sudah ada dan mempelajari literature-literatur yang ada. Kemudian melakukan analisis terhadap permasalahan dan solusinya serta melakukan perancangan sistem. Setelah itu dilakukan implementasi dan pengujian terhadap sistem yang telah jadi untuk mengambil simpulan 
Syahril Amin

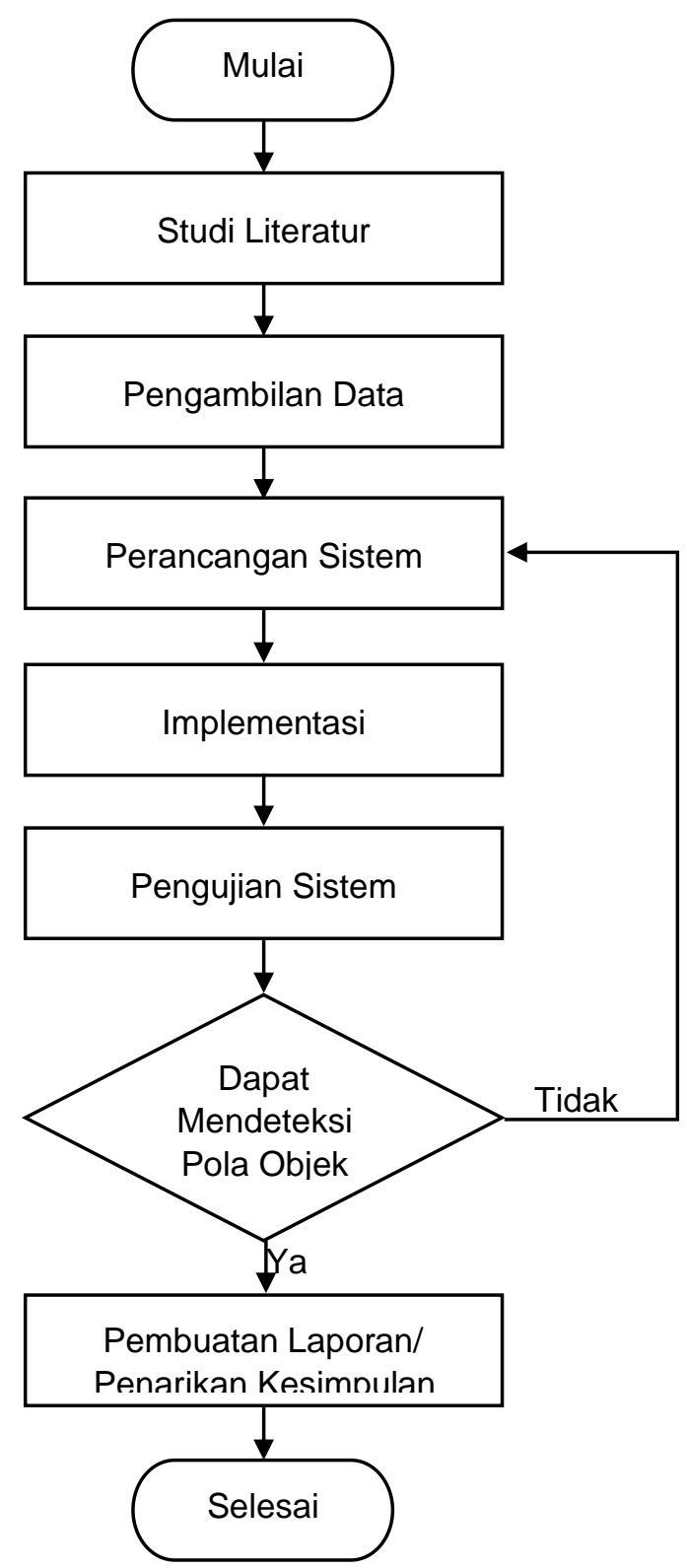

Gambar 2 Tahapan Penelitian

Rancangan Penelitian ini berfokus dalam perancangan aplikasi mobile dan menyajikan informasi berupa nama dan fungsi dari alat-alat praktik laboratorium Kimia. Smartphone yang diarahkan ke objek dapat menampilkan informasi Nama dan Fungsi objek. 

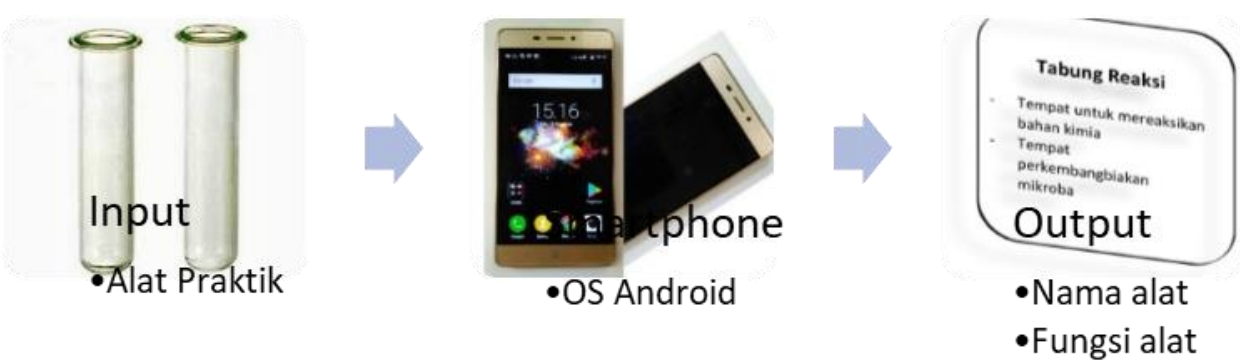

Gambar 3 Rancangan penelitian

\section{Hasil dan Pembahasan}

Software yang digunakan adalah Unity 5.3.4p4, Android SDK, Android NDK R10e, JDK 8u144, dan library Vuforia 6.2.10 yang diinstal pada PC pengembang dan menghasilkan file instalasi AlatKimia.apk. Dan aplikasi Vuforia Object Scanner 5.5.11 yang diinstal pada smartphone berbasis Android untuk memindai objek yang akan dibuat databasenya.

Selain software, pada penelitian ini digunakan alat bantu berupa Stage dengan latarbelakang berwarna abu-abu yang terbuat dari sehelai kain. Dan sebuah permukaan terbuat dari karton tebal $5 \mathrm{~mm}$ yang diatasnya diletakkan (ditempelkan) Vuforia Scanning Target yang dicetak diatas kertas ukuran A4.

Objek yang diuji setelah sistem selesai dibuat berjumlah 10 alat praktik laboratorium kimia, yaitu; Rak Tabung Reaksi 6 mata, Beker Glass 100 ml, Erlenmeyer 100 ml, Penjepit Tabung Reaksi, Klem Buret, Klem Buret Kaki 3, Neraca Digital, Neraca, Centrifuge, dan Miroskop.

Sistem diuji secara langsung atau realtime pada jarak $20 \mathrm{~cm}$ menggunakan Smartphone Android yang telah diinstal aplikasi Vuforia Object Scanner dan aplikasi Alat Praktik Kimia yang diarahkan pada alat-alat praktik laboratorium kimia.

Pengujian dilakukan dengan menggunakan 2 (dua) aplikasi. yang pertama adalah aplikasi Vuforia Object Scanner. Selain digunakan untuk memindai objek yang akan dibuat databasenya, aplikasi ini juga bisa digunakan untuk menguji objek yang dipindai sebelum dibuat databasenya. Aplikasi ini memiliki indikator berupa balok vertical berwarna hijau yang akan terlihat jika objek yang dipindai kemungkinan dapat dideteksi oleh sistem yang akan dibuat. 


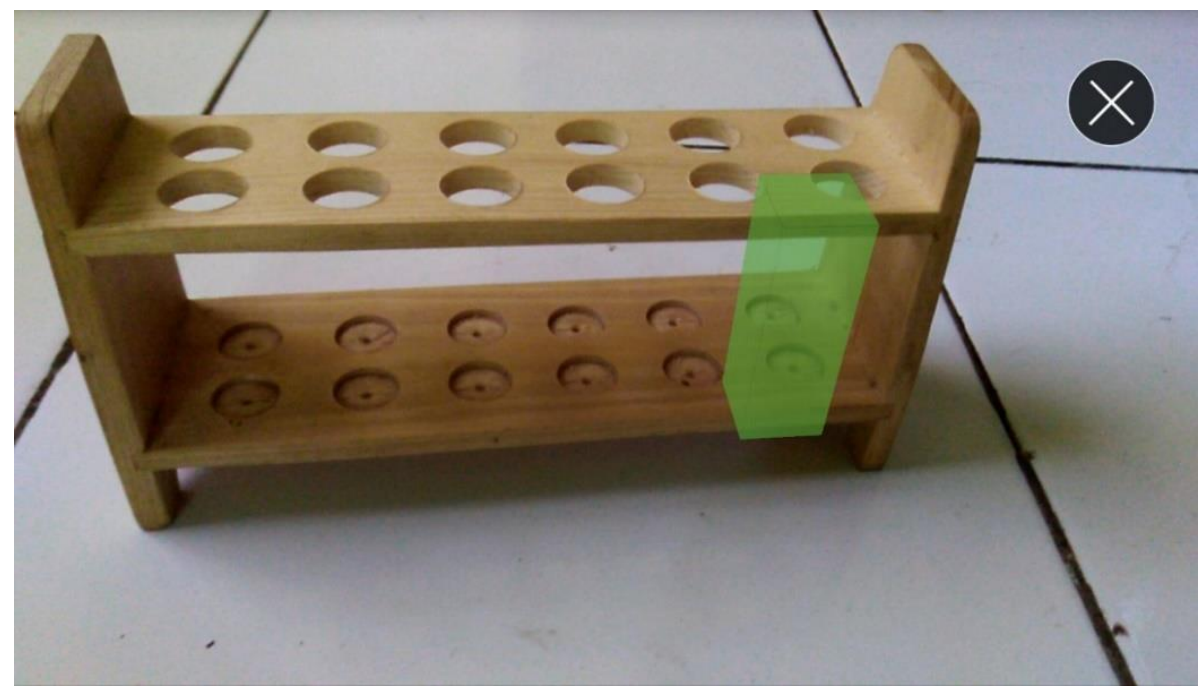

Gambar 4 Pengujian dengan aplikasi Vuforia Object Scanner

Aplikasi kedua yang digunakan pada pengujian adalah aplikasi atau sistem yang telah dibuat, yaitu AlatKimia. Setelah database diintegrasikan ke dalam sistem dan aplikasi telah selesai dibangun, aplikasi diinstal pada smartphone kemudian dijalankan dan kamera smartphone diarahkan pada objek yang akan dikenali. Apabila sistem dapat mengenali objek, maka sistem akan menampilkan Nama dan Fungsi dari objek yang berupa alat praktik laboratorium kimia tersebut pada layar smartphone.

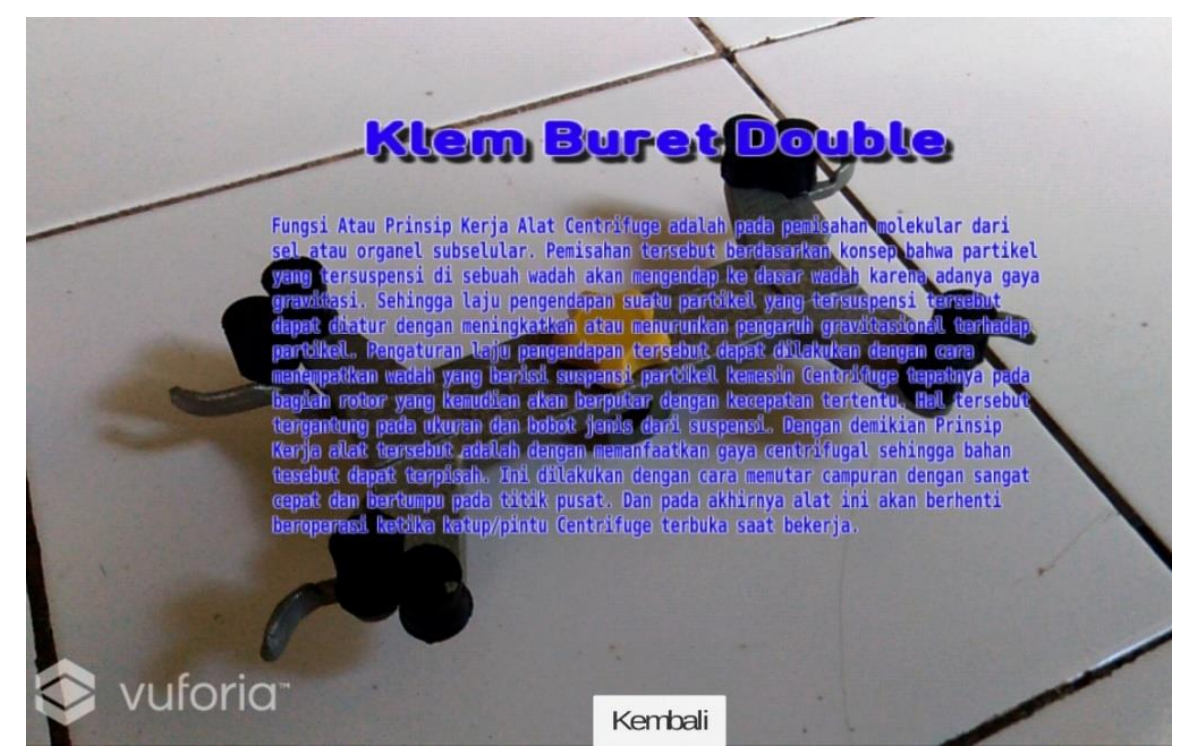

Gambar 5 Pengujian dengan aplikasi AlatKimia 


\section{Pengujian menggunakan aplikasi Vuforia Object Scanner}

Objek yang dapat dideteksi menggunakan Vuforia Object Scanner adalah objek yang mendapatkan point. Indikator point dapat dilihat pada sudut kiri atas aplikasi. Semakin banyak point yang didapatkan maka semakin besar peluang objek akan terdeteksi.

Tabel 1 Objek Permukaan Transparan

\begin{tabular}{llcccccccc}
\hline \multirow{2}{*}{ No } & \multirow{2}{*}{ Nama Alat } & I & II & III & IV & V & VI & VII & Jumlah \\
\hline 1 & Beker Glass $100 \mathrm{ml}$ & $\mathrm{X}$ & $\mathrm{x}$ & $\sqrt{ }$ & $\mathrm{X}$ & $\sqrt{ }$ & $\mathrm{x}$ & $\mathrm{x}$ & 2 \\
2 & Erlenmeyer $100 \mathrm{ml}$ & $\mathrm{X}$ & $\mathrm{x}$ & $\mathrm{x}$ & $\mathrm{X}$ & $\mathrm{x}$ & $\mathrm{x}$ & $\mathrm{x}$ & 0 \\
\hline
\end{tabular}

Table 1 menunjukkan pengaruh cahaya dan sifat permukaan objek yang transparan terhadap peluang objek agar dapat terdeteksi. Hal ini disebabkan karena permukaan objek yang transparan dapat memantulkan cahaya dan bayangan benda di sekitarnya sehingga pantulan cahaya dan bayangan benda di sekitarnya menutupi dan membentuk pola-pola pada permukaan objek. Selain dapat memantulkan cahaya dan bayangan benda di sekitarnya, objek dengan permukaan transparan tidak dapat dibedakan antara objek dan latar belakangnya sehingga objek menjadi tidak ada. Meskipun demikian, dari hasil pengujian pada table 2 menunjukkan bahwa ada peluang sebesar $14.28 \%$ objek tersebut dapat dikenali.

Tabel 2 Objek Permukaan Tidak Transparan Yang Tidak Memantulkan Cahaya Atau Bayangan

\begin{tabular}{llcccccccc}
\hline \multirow{2}{*}{ No } & \multirow{3}{*}{ Nama Alat } & \multicolumn{10}{c}{ Deteksi } \\
\cline { 3 - 8 } & & I & II & III & IV & V & VI & VII & Jumlah \\
\hline 1 & Rak Tabung Reaksi 6 Mata & $\sqrt{ }$ & $\sqrt{ }$ & $\sqrt{ }$ & $\sqrt{ }$ & $\sqrt{ }$ & $\sqrt{ }$ & $\sqrt{ }$ & 7 \\
2 & Penjepit Tabung Reaksi & $\sqrt{ }$ & $\sqrt{ }$ & $\sqrt{ }$ & $X$ & $\sqrt{ }$ & $\sqrt{ }$ & $\sqrt{ }$ & 6 \\
\hline
\end{tabular}

Table 2 menunjukkan pengaruh cahaya dan sifat permukaan objek yang tidak transparan terhadap peluang objek agar dapat terdeteksi. Hal ini disebabkan karena permukaan objek yang tidak transparan tidak memantulkan cahaya dan bayangan benda di sekitarnya sehingga tidak ada pantulan cahaya dan bayangan benda di sekitarnya yang menutupi dan membentuk pola-pola pada permukaan objek. Selain tidak memantulkan cahaya dan bayangan benda di sekitarnya, objek dengan permukaan tidak transparan dapat dibedakan antara objek dan latar belakangnya sehingga objek menjadi ada. Dengan demikian, dari hasil pengujian pada table 2 menunjukkan bahwa peluang sebesar $92.86 \%$ objek tersebut dapat dikenali. 
Tabel 3 Objek Permukaan Tidak Transparan Yang Memantulkan Cahaya Atau Bayangan

\begin{tabular}{llcccccccc}
\hline \multirow{2}{*}{ No } & \multirow{2}{*}{ Nama Alat } & \multicolumn{10}{c}{ Deteksi } \\
\cline { 3 - 9 } & & I & II & III & IV & V & VI & VII & Jumlah \\
\hline 1 & Klem Buret & X & X & $\sqrt{ }$ & $\sqrt{ }$ & $\sqrt{ }$ & $\sqrt{ }$ & $\sqrt{ }$ & 5 \\
\hline 2 & Klem Buret Double & $X$ & $\sqrt{ }$ & $\sqrt{ }$ & $\sqrt{ }$ & $\sqrt{ }$ & $\sqrt{ }$ & $\sqrt{ }$ & 6 \\
\hline 3 & Neraca Digital & $\sqrt{ }$ & $\sqrt{ }$ & $X$ & $X$ & $\sqrt{ }$ & $\sqrt{ }$ & $\sqrt{ }$ & 5 \\
\hline 4 & Neraca Ohaus Tiga Lengan & $X$ & $\sqrt{ }$ & $\sqrt{ }$ & $X$ & $\sqrt{ }$ & $X$ & $X$ & 3 \\
\hline 5 & Centrifuge & $\sqrt{ }$ & $\sqrt{ }$ & $\sqrt{ }$ & $\sqrt{ }$ & $\sqrt{ }$ & $\sqrt{ }$ & $X$ & 6 \\
\hline 6 & Mikroskop & $X$ & $\sqrt{ }$ & $\sqrt{ }$ & $\sqrt{ }$ & $\sqrt{ }$ & $\sqrt{ }$ & $\sqrt{ }$ & 6 \\
\hline
\end{tabular}

Table 3 menunjukkan pengaruh cahaya dan sifat permukaan objek yang tidak transparan terhadap peluang objek agar dapat terdeteksi. Hal ini disebabkan karena permukaan objek yang tidak transparan ada yang dapat memantulkan cahaya dan bayangan benda di sekitarnya sehingga pantulan cahaya dan bayangan benda di sekitarnya dapat menutupi dan membentuk pola-pola pada permukaan objek. Khususnya permukaan yang bersifat mengkilap. Selain dapat memantulkan cahaya dan bayangan benda di sekitarnya, objek dengan permukaan tidak transparan dapat dibedakan antara objek dan latar belakangnya sehingga objek menjadi ada. Dengan demikian, dari hasil pengujian pada table 3 menunjukkan bahwa peluang sebesar $73.80 \%$ objek tersebut dapat dikenali.

Berdasarkan pengujian dengan aplikasi Vuforia Object Scanner, objek dengan sifat permukaan transparan yang dapat memantulkan cahaya dan bayangan benda di sekitarnya hanya memiliki peluang sebesar $14.28 \%$ untuk terdeteksi. Sedangkan objek dengan sifat permukaan tidak transparan yang tidak memantulkan cahaya dan bayangan disekitarnya dan objek dengan sifat permukaan tidak transparan namun dapat memantulkan cahaya dan bayangan disekitarnya, memiliki peluang lebih besar untuk terdeteksi, yaitu sebesar $92.86 \%$ dan $73.80 \%$.

Berdasarkan peluang yang diperoleh dari pengujian ketiga sifat objek di atas, maka objek dapat dibangunkan aplikasi untuk mengenalinya dengan menggunakan Vuforia Library.

\section{Pengujian aplikasi AlatKimia (Sistem yang telah dibangun)}

Sistem atau aplikasi yang telah selesai dibangun selanjutnya diuji tingkat keberhasilannya. Aplikasi tersebut diberi nama Alat Kimia. Aplikasi akan diuji sebanyak 7 (tujuh) kali terhadap masing-masing objek berdasarkan sifat permukaannya, dengan memperhatikan persentase keberhasilan aplikasi mendeteksi objek. Berikut adalah Tabel hasil pengujian aplikasi Alat Kimia:

Tabel 4 Pengujian Aplikasi Alat Kimia Dengan Objek Permukaan Transparan

\begin{tabular}{|c|c|c|c|c|c|c|c|c|c|}
\hline \multirow{2}{*}{ No } & \multirow{2}{*}{ Nama Alat } & \multicolumn{8}{|c|}{ Dikenal } \\
\hline & & I & II & III & IV & $\mathbf{V}$ & VI & VII & Jumlah \\
\hline 1 & Beker Glass $100 \mathrm{ml}$ & $\mathrm{X}$ & $\mathrm{X}$ & $\mathrm{X}$ & $\mathrm{X}$ & $\mathrm{X}$ & $\mathrm{X}$ & $\bar{X}$ & 0 \\
\hline 2 & Erlenmeyer $100 \mathrm{ml}$ & $\mathrm{X}$ & $X$ & $\mathrm{X}$ & $X$ & $\mathrm{X}$ & $X$ & $\mathrm{X}$ & 0 \\
\hline
\end{tabular}


Table 4 menunjukkan pengaruh cahaya dan sifat permukaan objek yang transparan terhadap kemampuan aplikasi mengenali objek. Hal ini disebabkan karena permukaan objek yang transparan dapat memantulkan cahaya dan bayangan benda di sekitarnya sehingga pantulan cahaya dan bayangan benda di sekitarnya menutupi dan membentuk pola-pola pada permukaan objek. Selain dapat memantulkan cahaya dan bayangan benda di sekitarnya, objek dengan permukaan transparan tidak dapat dibedakan antara objek dan latar belakangnya sehingga objek menjadi tidak ada. Dengan demikian, dari hasil pengujian pada table 5 menunjukkan bahwa aplikasi tidak dapat mengenali objek dengan sifat tersebut.

Tabel 5 Objek Permukaan Tidak Transparan yang Tidak Memantulkan Cahaya Atau Bayangan

\begin{tabular}{llcccccccc}
\hline \multirow{2}{*}{ No } & \multicolumn{1}{c}{ Nama Alat } & \multicolumn{10}{c}{ Dikenal } \\
\cline { 3 - 9 } & & I & II & III & IV & V & VI & VII & Jumlah \\
\hline 1 & Rak Tabung Reaksi 6 Mata & $\sqrt{ }$ & $\sqrt{ }$ & $X$ & $X$ & $\sqrt{ }$ & $\sqrt{ }$ & $\sqrt{ }$ & 5 \\
2 & Penjepit Tabung Reaksi & $X$ & $\sqrt{ }$ & $\sqrt{ }$ & $\sqrt{ }$ & $X$ & $\sqrt{ }$ & $\sqrt{ }$ & 5 \\
\hline
\end{tabular}

Table 5 menunjukkan pengaruh cahaya dan sifat permukaan objek yang tidak transparan terhadap peluang objek agar dapat dikenali. Hal ini disebabkan karena permukaan objek yang tidak transparan tidak memantulkan cahaya dan bayangan benda di sekitarnya sehingga tidak ada pantulan cahaya dan bayangan benda di sekitarnya yang menutupi dan membentuk pola-pola pada permukaan objek. Selain tidak memantulkan cahaya dan bayangan benda di sekitarnya, objek dengan permukaan tidak transparan dapat dibedakan antara objek dan latar belakangnya sehingga objek menjadi ada. Dengan demikian, dari hasil pengujian pada table 5 menunjukkan bahwa aplikasi mampu mengenali objek tersebut dengan persentasi $71.42 \%$

Tabel 6 Objek Permukaan Tidak Transparan yang Memantulkan Cahaya Atau Bayangan

\begin{tabular}{|c|c|c|c|c|c|c|c|c|c|}
\hline \multirow{2}{*}{ No } & \multirow{2}{*}{ Nama Alat } & \multicolumn{8}{|c|}{ Dikenal } \\
\hline & & $\mathbf{I}$ & II & III & IV & $\mathbf{V}$ & VI & VII & Jumlah \\
\hline 1 & Klem Buret & $\mathrm{X}$ & $\mathrm{X}$ & $\mathrm{X}$ & $\mathrm{X}$ & $\sqrt{ }$ & $\sqrt{ }$ & $\sqrt{ }$ & 3 \\
\hline 2 & Klem Buret Double & $\sqrt{ }$ & $\sqrt{ }$ & $\sqrt{ }$ & $\mathrm{X}$ & $X$ & $\sqrt{ }$ & $\mathrm{X}$ & 4 \\
\hline 3 & Neraca Digital & $X$ & $\sqrt{ }$ & $\sqrt{ }$ & $X$ & $\sqrt{ }$ & $\sqrt{ }$ & $\mathrm{X}$ & 4 \\
\hline 4 & Neraca Ohaus Tiga Lengan & $\sqrt{ }$ & $\sqrt{ }$ & $\mathrm{X}$ & $\sqrt{ }$ & $\mathrm{X}$ & $\mathrm{X}$ & $\mathrm{X}$ & 3 \\
\hline 5 & Centrifuge & $\sqrt{ }$ & $\sqrt{ }$ & $X$ & $\sqrt{ }$ & $\mathrm{X}$ & $\mathrm{X}$ & $\sqrt{ }$ & 4 \\
\hline 6 & Mikroskop & $\sqrt{ }$ & $X$ & $X$ & $X$ & $\sqrt{ }$ & $\sqrt{ }$ & $\sqrt{ }$ & 4 \\
\hline
\end{tabular}

Table 6 menunjukkan pengaruh cahaya dan sifat permukaan objek yang tidak transparan terhadap kemampuan aplikasi untuk mengenali objek. Hal ini disebabkan karena permukaan objek yang tidak transparan ada yang dapat 
memantulkan cahaya dan bayangan benda di sekitarnya sehingga pantulan cahaya dan bayangan benda di sekitarnya dapat menutupi dan membentuk pola-pola pada permukaan objek. Khususnya permukaan yang bersifat mengkilap. Selain dapat memantulkan cahaya dan bayangan benda di sekitarnya, objek dengan permukaan tidak transparan dapat dibedakan antara objek dan latar belakangnya sehingga objek menjadi ada. Dengan demikian, dari hasil pengujian pada table 7 menunjukkan bahwa peluang sebesar $52.38 \%$ objek tersebut dapat dikenali.

Berdasarkan pengujian dengan aplikasi Alat Kimia, objek dengan sifat permukaan transparan yang dapat memantulkan cahaya dan bayangan benda di sekitarnya tidak dikenali. Sedangkan objek dengan sifat permukaan tidak transparan yang tidak memantulkan cahaya dan bayangan disekitarnya dan objek dengan sifat permukaan tidak transparan namun dapat memantulkan cahaya dan bayangan disekitarnya, dapat dikenali, dengan persentase sebesar $71.42 \%$ dan $52.38 \%$.

\section{Kesimpulan}

Pengujian menunjukkan bahwa rancangan model pembelajaran menggunakan model peraga sebagai media untuk mengidentifikasi alat-alat praktik laboratorium kimia berbasis AR dengan menggunakan smartphone Android menghasilkan sebuah aplikasi Alat Kimia yang dapat mengenali objek dengan sifat permukaan tidak transparan yang tidak memantulkan cahaya dan bayangan benda di sekitarnya dengan persentase $71.42 \%$, serta dapat mengenali objek dengan sifat permukaan tidak transparan yang dapat memantulkan cahaya dan bayangan benda di sekitarnya dengan persentase $52.38 \%$. Hal ini dipengaruhi oleh permukaan benda yang memantulkan cahaya dan bayangan benda di sekitarnya sehingga menutup dan merubah pola pada permukaan. Sedangkan objek dengan sifat permukaan transparan yang memantulkan cahaya dan bayangan benda di sekitarnya tidak dapat dikenali karena sifat transparan pada permukaan objek menyebabkan objek dan latar belakangnya tidak dapat dipisahkan. Sedangkan sifat permukaan objek yang dapat memantulkan cahaya dan bayangan benda di sekitarnya dapat menutupi dan merubah pola-pola pada permukaan objek sehingga tidak dapat dikenali. 


\section{BIBLIOGRAFI}

Abdurokhim, Abdurokhim. (2016). Analisis Komparatif Penggunaan Sistem Informasi Perbankan antara Bank Syariah aan Bank Konvensional. Syntax Literate; Jurnal Ilmiah Indonesia, 1(1), 41-54.

Angriani, Liza. (2020). Perancangan Model Pengenalan Kebudayaan Papua Secara Interaktif Berbasis Android. Jiska (Jurnal Informatika Sunan Kalijaga), 5(1), 4255 .

Chafied, Muchammad, Hakkun, Rizky, \& Asmara, Rengga. (2010). Brosur interaktif berbasis augmented reality. EEPIS Final Project.

Fam, Kim Shyan, \& Grohs, Reinhard. (2007). Cultural values and effective executional techniques in advertising. International Marketing Review, 24(5), 519-538.

Hambali, Syahruni, Akib, Erwin, \& Azis, Sitti Aida. (2020). Pengaruh Media Animasi Terhadap Keterampilan Menulis Cerita Murid Kelas V SD Se-Kota Makassar. Syntax Literate; Jurnal Ilmiah Indonesia, 5(6), 182-191.

Hidayat, Tonny. (2014). Penerapan Teknologi Augmented Reality Sebagai Model Media Edukasi Kesehatan Gigi Bagi Anak. Creative Information Technology Journal, 2(1), 77-92.

Mustaqim, Ilmawan. (2016). Pemanfaatan Augmented Reality sebagai media pembelajaran. Jurnal Pendidikan Teknologi Dan Kejuruan, 13(2), 174-183.

Mustaqim, Ilmawan. (2017). Pengembangan Media Pembelajaran Berbasis Augmented Reality. Jurnal Edukasi Elektro, 1(1).

Ogedebe, Peter M., \& Jacob, Babatunde Peter. (2012). Software Prototyping: A Strategy to Use When User Lacks Data Processing Experience.

Prastiwi, Prastiwi, \& Yuniasanti, Reny. (2014). Hubungan Antara Model Komunikasi Dua Arah Antara Atasan Dan Bawahan Dengan Motivasi Kerja Pada Bintara Di Polresta Yogyakarta. Jurnal Psikologi Integratif, 2(2).

Rosten, Edward, \& Drummond, Tom. (2006). Machine learning for high-speed corner detection. European Conference on Computer Vision, 430-443. Springer.

Saputra, Ari Kurniawan. (2016). Aplikasi Deteksi Objek Menggunakan Histogram Of Oriented Gradient Untuk Modul Sistem Cerdas Pada Robot Nao. Universitas Bandar Lampung, Lampung.

Vitono, H., Nasution, H., \& Anra, H. (2016). Implementasi Markerless Augmented Reality Sebagai Media Informasi Koleksi Museum Berbasis Android (Studi Kasus: Museum Kalimantan Barat). Jurnal Sistem Dan Teknologi Informasi (JustIN), 4(2), 239-245. 
Syahril Amin

Yudiantika, Aditya Rizki, Pasinggi, Eko Suripto, Sari, Irma Permata, \& Hantono, Bimo Sunarfri. (2013). Implementasi Augmented Reality Di Museum: Studi Awal Perancangan Aplikasi Edukasi Untuk Pengunjung Museum. Yogyakarta: Konferensi Nasional Teknologi Informasi Dan Komunikasi (KNASTIK), Fakultas Teknologi Informasi, Universitas Kristen Duta Wacana. 